\title{
Towards IASI-New Generation (IASI-NG): impact of improved spectral resolution and radiometric noise on the retrieval of thermodynamic, chem- istry and climate variables
}

\author{
C. Crevoisier et al.
}

Correspondence to: C. Crevoisier (cyril.crevoisier@1md.polytechnique.fr) 
2

(a) IRS1/IASI

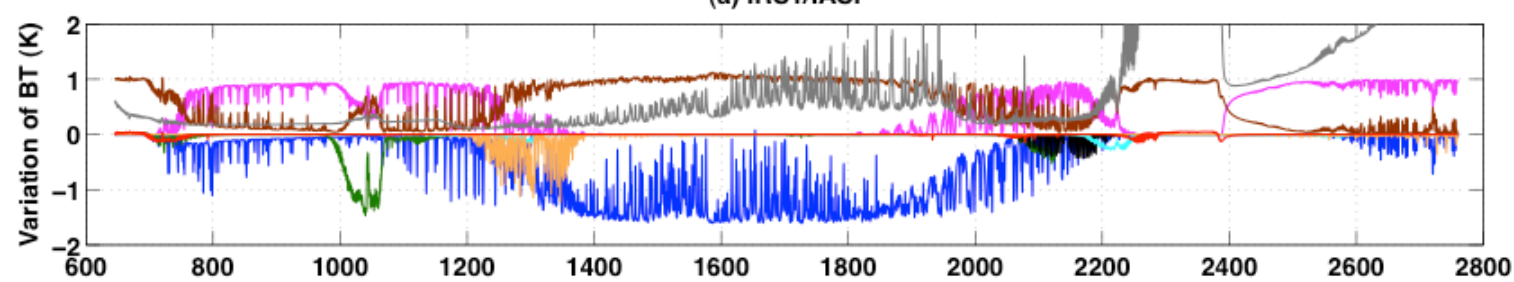

(b) IRS2/ASI-NG

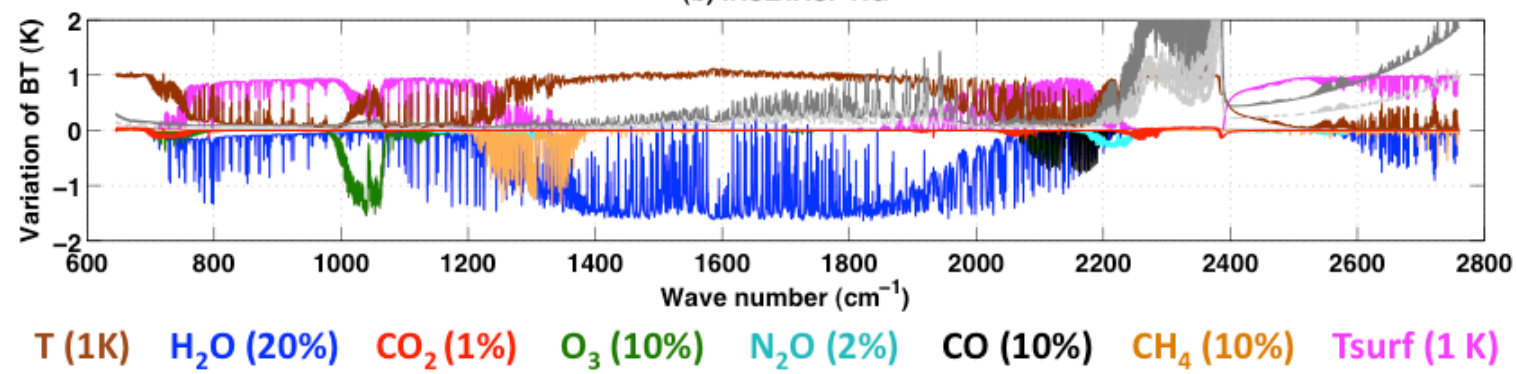

Figure S1. Same as Fig. 2 but for temperate TIGR situations. 
(a) IRS1/IASI

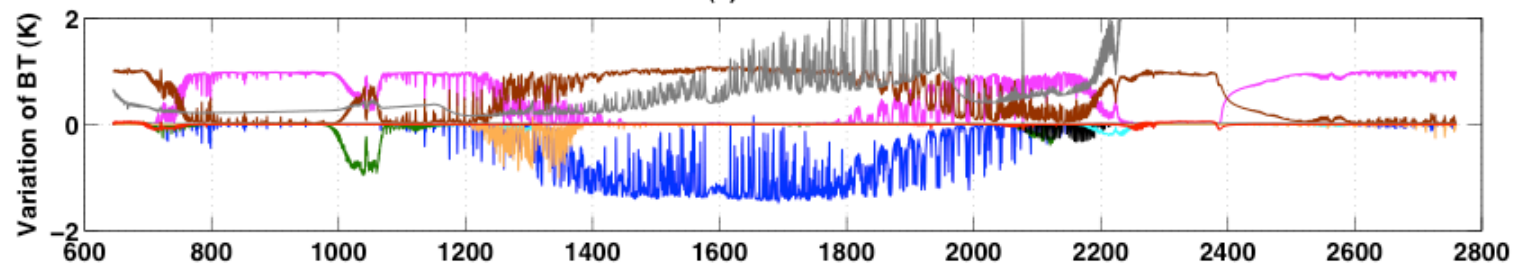

(b) IRS2/IASI-NG

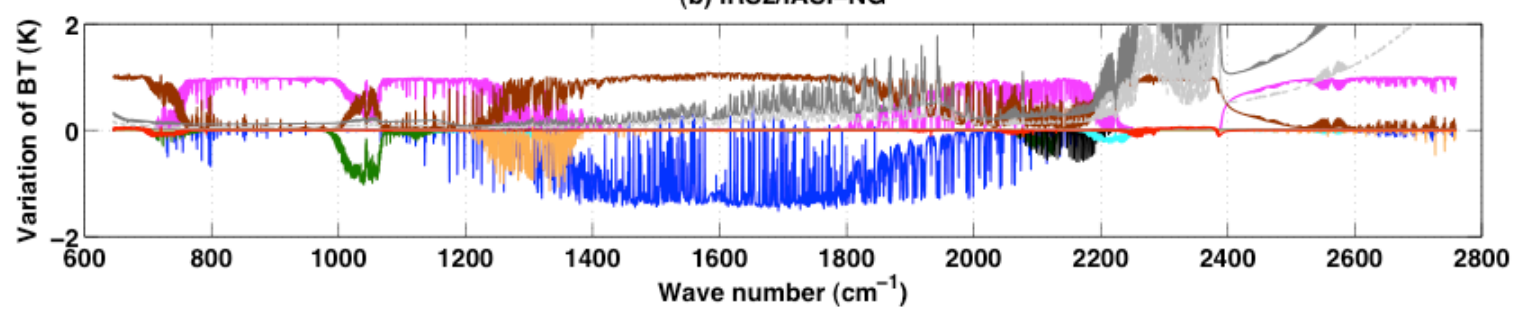

$\begin{array}{clllllll}\mathrm{T}(1 \mathrm{~K}) & \mathrm{H}_{2} \mathrm{O}(20 \%) & \mathrm{CO}_{2}(1 \%) & \mathrm{O}_{3}(10 \%) & \mathrm{N}_{2} \mathrm{O}(2 \%) & \mathrm{CO}(10 \%) & \mathrm{CH}_{4}(10 \%) & \text { Tsurf }(1 \mathrm{~K})\end{array}$

2 Figure S2. Same as Fig. 2 but for polar TIGR situations. 